\title{
Adenocarcinoma of the Lung Acquiring Resistance to Afatinib by Transformation to Small Cell Carcinoma: A Case Report
}

\author{
Jun Nishimura ${ }^{a}$ Yosuke Miyamoto $^{b}$ Nobukazu Fujimoto ${ }^{c}$ Taichi Ozeki $^{a}$ \\ Kenji Takada ${ }^{a}$ Michiko Asano $^{b}$ Yasuko Fuchimoto ${ }^{b}$ Sae Wadab \\ Shinji Ozaki ${ }^{b}$ Takumi Kishimoto $^{\text {a }}$ \\ ${ }^{a}$ Department of Medicine, Okayama Rosai Hospital, Okayama, Japan; ${ }^{b}$ Department of \\ Pulmonary Medicine, Okayama Rosai Hospital, Okayama, Japan; 'Department of Medical \\ Oncology, Okayama Rosai Hospital, Okayama, Japan
}

\section{Keywords}

Adenocarcinoma - Afatinib - Small cell carcinoma - Irinotecan · Drug resistance ·

Transformation

\begin{abstract}
A 65-year-old woman visited our hospital due to right chest pain and dyspnea on exertion. Chest radiography revealed decreased permeability of the right lung. Computed tomography demonstrated a huge mass in the right upper lobe and right pleural effusion. Right pleural effusion cytology yielded a diagnosis of adenocarcinoma and was positive for mutation of epidermal growth factor receptor (EGFR; exon 21 L858R). Afatinib was selected for the initial treatment. Multiple tumors regressed remarkably, but then rapidly progressed 3 months later. We performed re-biopsy to detect the mechanism of resistance to afatinib. Histopathology revealed a mixture of small cell carcinoma (SCC) and adenocarcinoma harboring same EGFR mutation. To the best of our knowledge, this is the first report of transformation to SCC after treatment with afatinib.


 Oncology}

\section{Introduction}

Lung cancers harboring epidermal growth factor receptor (EGFR) mutations usually respond to EGFR tyrosine kinase inhibitors (TKIs), but most acquire resistance [1, 2]. Transformation of the tumor has been reported to be one of the mechanisms of acquired resistance after treatment with first-generation EGFR-TKIs [3]. However, few reports have described transformation during treatment with the second-generation EGFR-TKI afatinib [4]. We report a case of adenocarcinoma of the lung that acquired resistance to afatinib via transformation to small cell carcinoma (SCC).

\section{Case Report}

A 65-year-old woman visited our hospital due to right chest pain and dyspnea on exertion. A chest radiograph revealed decreased permeability of the right lung (Fig. 1a). Computed tomography (CT) demonstrated a huge mass in the right upper lobe (Fig. 1b) and right pleural effusion. In addition, multiple masses were detected on the left lung, liver, and left adrenal grand, as well as mediastinal lymphadenopathy. Pathological examination of the right pleural effusion and a transbronchial biopsy from the right upper bronchus yielded a diagnosis of adenocarcinoma of the lung. Because an EGFR mutation (exon 21 L858R) was detected, treatment with afatinib was initiated.

Multiple tumors remarkably regressed in 1 month, but paronychia (grade 3) appeared in 2 months. Due to difficulties in daily life, the treatment was interrupted for 2 weeks. CT images 3 months after the initial treatment demonstrated growth of the tumors in the lung. We performed another transbronchial biopsy to determine the mechanisms of resistance to afatinib. Histopathological examination revealed a mixture of SCC and adenocarcinoma (Fig. 2) harboring the same EGFR mutation as the initial biopsy specimen. Systemic chemotherapy consisting of cisplatin and irinotecan was administered, but no tumor regression was evident and carcinomatous pericarditis occurred. In addition, the patient complained of consciousness disorder and convulsions. Lumbar puncture identified adenocarcinoma cells in the cerebrospinal fluid. The patient was diagnosed with carcinomatous meningitis and erlotinib treatment was administered. However, no symptomatic improvement occurred and the patient died 5 months after the initial diagnosis. Autopsy was not allowed.

\section{Discussion}

In lung cancers harboring EGFR mutations, EGFR-TKIs demonstrate a favorable response, but drug resistance emerges in most cases. A transformation of adenocarcinoma to SCC is one of the resistance mechanisms in first-generation EGFR-TKIs and occurs in 14\% of resistant cases, in which the same EGFR mutation is found before and after the changes [5]. An amplification of MET, a high affinity tyrosine kinase receptor for hepatocyte growth factor, and a T790M mutation have been reported as resistance mechanisms of the secondgeneration EGFR-TKI afatinib [4]. However, to the best of our knowledge, this is the first report of transformation to SCC after afatinib treatment.

In the current case, SCC cells were found 3 months after the initial treatment with afatinib. After the chemotherapy for SCC, the carcinomatous meningitis progressed rapidly. Thus, we hypothesized that a very early stage of SCC development was observed in the cur- 
rent case. Although there is a possibility that adenocarcinoma and SCC coexisted from the initial diagnosis, a transbronchial biopsy from the same spot demonstrated adenocarcinoma alone at the time of the initial diagnosis and adenocarcinoma and SCC at the re-biopsy. We consider these findings to support our hypothesis.

When resistance to an EGFR-TKI occurs in lung cancer harboring an EGFR mutation, rebiopsy is recommended to reveal the resistance mechanisms. For cases with a T790M mutation in exon 20, osimertinib has been reported to be a promising treatment option [6]. Recently, the utility of liquid biopsy has been reported for the detection of the T790M mutation [7]. However, to date, SCC transformation cannot be detected by liquid biopsy. In cases in which EGFR-TKI treatment fails, re-biopsy should be applied to reveal the resistance mechanisms and aid in the selection an appropriate treatment.

Favorable results of systemic chemotherapy consisting of platinum and etoposide or irinotecan have been reported in cases of SCC transformation [8], but little response was observed in the current case and the adenocarcinoma progressed rapidly. The effect of EGFRTKIs for transformed SCC is reported to be limited [9]. A treatment strategy for transformed SCC and existing adenocarcinoma should be established.

In conclusion, we reported a case of EGFR-mutated adenocarcinoma of the lung that transformed to SCC.

\section{Acknowledgments}

This work was supported by "the research and development and the dissemination projects related to the 9 fields of occupational injuries and illnesses" of the Japan Labour Health and Welfare Organization and by grants-in-aid from the Ministry of Health, Labor and Welfare, Japan.

\section{Statement of Ethics}

The authors have no ethical conflicts to disclose.

\section{Disclosure Statement}

The authors have no conflicts of interest to declare.

\section{References}

1 Maemondo M, Minegishi Y, Inoue A, Kobayashi K, Harada M, Okinaga S, Morikawa N, Oizumi S, Tanaka T, Isobe H, Kudoh S, Hagiwara K, Nukiwa T, Gemma A: First-line gefitinib in patients aged 75 or older with advanced non-small cell lung cancer harboring epidermal growth factor receptor mutations: NEJ 003 study. J Thorac Oncol 2012;7:1417-1422.

-2 Rosell R, Carcereny E, Gervais R, Vergnenegre A, Massuti B, Felip E, Palmero R, Garcia-Gomez R, Pallares C, Sanchez JM, Porta R, Cobo M, Garrido P, Longo F, Moran T, Insa A, De Marinis F, Corre R, Bover I, Illiano A, Dansin E, de Castro J, Milella M, Reguart N, Altavilla G, Jimenez U, Provencio M, Moreno MA, Terrasa J, Munoz-Langa J, Valdivia J, Isla D, Domine M, Molinier O, Mazieres J, Baize N, Garcia-Campelo R, Robinet G, Rodriguez-Abreu D, Lopez-Vivanco G, Gebbia V, Ferrera-Delgado L, Bombaron P, Bernabe R, Bearz A, Artal A, Cortesi E, Rolfo C, Sanchez-Ronco M, Drozdowskyj A, Queralt C, de Aguirre I, Ramirez JL, Sanchez JJ, Molina MA, Taron M, Paz-Ares L: Erlotinib versus standard chemotherapy as 


\section{Case Reports in Oncology}

\begin{tabular}{l|l}
\hline Case Rep Oncol 2017;10:666-670 \\
\hline DOI: $10.1159 / 000479147$ & $\begin{array}{l}\text { C 2017 The Author(s). Published by S. Karger AG, Basel } \\
\text { www.karger.com/cro }\end{array}$ \\
\hline
\end{tabular}

Nishimura et al.: Adenocarcinoma of the Lung Acquiring Resistance to Afatinib by Transformation to Small Cell Carcinoma: A Case Report

first-line treatment for European patients with advanced EGFR mutation-positive non-small-cell lung cancer (EURTAC): a multicentre, open-label, randomised phase 3 trial. Lancet Oncol 2012;13:239-246

$>3$ Yu HA, Arcila ME, Rekhtman N, Sima CS, Zakowski MF, Pao W, Kris MG, Miller VA, Ladanyi M, Riely GJ: Analysis of tumor specimens at the time of acquired resistance to EGFR-TKI therapy in 155 patients with EGFR-mutant lung cancers. Clin Cancer Res 2013;19:2240-2247.

-4 Wu SG, Liu YN, Tsai MF, Chang YL, Yu CJ, Yang PC, Yang JC, Wen YF, Shih JY: The mechanism of acquired resistance to irreversible EGFR tyrosine kinase inhibitor-afatinib in lung adenocarcinoma patients. Oncotarget 2016;7:12404-12413.

-5 Sequist LV, Waltman BA, Dias-Santagata D, Digumarthy S, Turke AB, Fidias P, Bergethon K, Shaw AT, Gettinger S, Cosper AK, Akhavanfard S, Heist RS, Temel J, Christensen JG, Wain JC, Lynch TJ, Vernovsky K, Mark EJ, Lanuti M, Iafrate AJ, Mino-Kenudson M, Engelman JA: Genotypic and histological evolution of lung cancers acquiring resistance to EGFR inhibitors. Sci Transl Med 2011;3:75ra26.

-6 Mok TS, Wu YL, Ahn MJ, Garassino MC, Kim HR, Ramalingam SS, Shepherd FA, He Y, Akamatsu H, Theelen WS, Lee CK, Sebastian M, Templeton A, Mann H, Marotti M, Ghiorghiu S, Papadimitrakopoulou VA: Osimertinib or platinum-pemetrexed in EGFR T790M-positive lung cancer. N Engl J Med 2017;376:629-640.

7 Sueoka-Aragane N, Katakami N, Satouchi M, Yokota S, Aoe K, Iwanaga K, Otsuka K, Morita S, Kimura S, Negoro S: Monitoring EGFR T790M with plasma DNA from lung cancer patients in a prospective observational study. Cancer Sci 2016;107:162-167.

-8 Oser MG, Niederst MJ, Sequist LV, Engelman JA: Transformation from non-small-cell lung cancer to small-cell lung cancer: molecular drivers and cells of origin. Lancet Oncol 2015;16:e165-e172.

$\$ 9$ Niederst MJ, Sequist LV, Poirier JT, Mermel CH, Lockerman EL, Garcia AR, Katayama R, Costa C, Ross KN, Moran T, Howe E, Fulton LE, Mulvey HE, Bernardo LA, Mohamoud F, Miyoshi N, VanderLaan PA, Costa DB, Janne PA, Borger DR, Ramaswamy S, Shioda T, Iafrate AJ, Getz G, Rudin CM, Mino-Kenudson M, Engelman JA: RB loss in resistant EGFR mutant lung adenocarcinomas that transform to small-cell lung cancer. Nat Commun 2015;6:6377.
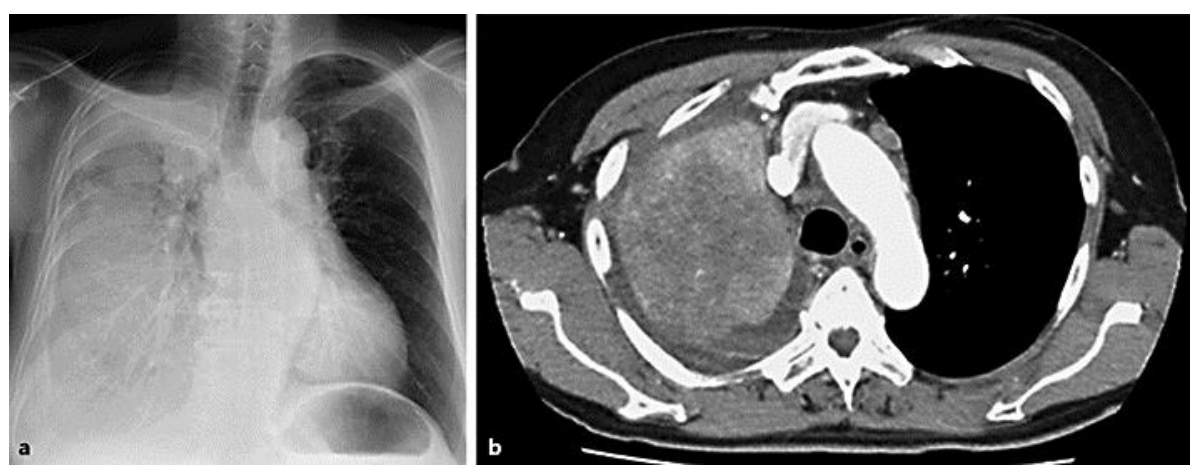

Fig. 1. a Chest radiograph showing decreased permeability of the right lung. b CT image of the chest demonstrating a huge mass in the right lung and right pleural effusion. 


\section{Case Reports in Oncology}

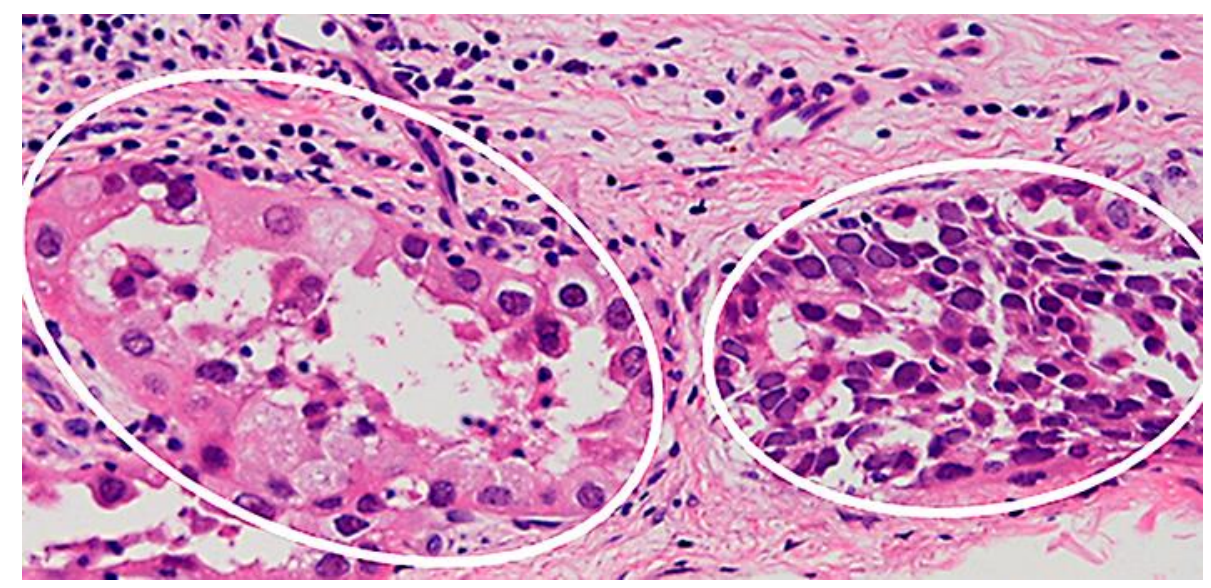

Fig. 2. Pathological analysis of the transbronchial re-biopsy specimen revealed adenocarcinoma (left circle) and small cell carcinoma (right circle). 